\title{
MURCIÉLAGOS DEL ARCHIPIÉLAGO DE SABANA-CAMAGÜEY, CUBA
}

\author{
CARLOS A. MANCINA ${ }^{1}$, ABEL HERNÁNDEZ-MUÑOZ ${ }^{2}$ \\ Y ARTURO HERNÁNDEZ-MARRERO ${ }^{1}$
}
1. Instituto de Ecología y Sistemática, Carretera de Varona km. 31/2 Boyeros, A.P. 8029
Ciudad de La Habana, Cuba.e-mail: biokarst@ama.cu
2. Grupo "Samá", Sociedad Espeleológica de Cuba. Ave 9na y 84, Playa. Ciudad de La Habana, Cuba.

Palabras clave: Murciélagos, Distribución, Archipiélago Sabana-Camagüey, Cuba.

El Archipiélago de Sabana-Camagüey (ASC) ocupa una franja de aproximadamente $465 \mathrm{Km}$ a lo largo de la zona norte central de Cuba entre Punta Hicacos y la Bahía de Nuevitas (Fig. 1). Existen 2,517 cayos con un área de 3,400 Km². Estos cayos presentan varias formaciones vegetales, como bosques semideciduos, bosques siempreverdes micrófilos, matorrales xeromorfos costeros y los bosques de mangle con predominancia de Rhizophora mangle los cuales cubren casi la totalidad de los cayos más pequeños. La fauna presenta elevados valores de endemismo entre los que se destacan los moluscos gasterópodos y reptiles. Esta región es un sitio de importancia para las aves residentes y migratorias lo que le concede a la región valores nacionales y regionales (Alcolado et al., 1999).

Poco se conoce sobre la fauna de mamíferos que habitan los cayos del Archipiélago cubano. Estos representan la localidad tipo y única conocida de cuatro especies de jutías (Rodentia: Capromyidae) en peligro de extinción (Berovides y Comas, 1991). Hasta hace pocos años la única referencia sobre la existencia de murciélagos en los cayos fue dada por Varona (1970), quien reportó a Macrotus waterhousii en una cueva de Cayo Santa María, Archipiélago de Sabana. Posteriormente González et al. (1994) realizaron un inventario de los mamíferos del Archipiélago de Camagüey y registraron cinco especies.

Desde finales de la década de 1980 del siglo pasado se comenzaron a realizar prospecciones científicas en los cayos del norte de Cuba, con el fin de implementar planes de conservación y manejo motivado por el desarrollo turístico planificado para la región. El objetivo de esta nota es brindar la información recopilada en 12 expediciones, realizadas entre 1989 y 2001, sobre la composición y distribución de los murciélagos que habitan el Archipiélago de Sabana-Camagüey. 


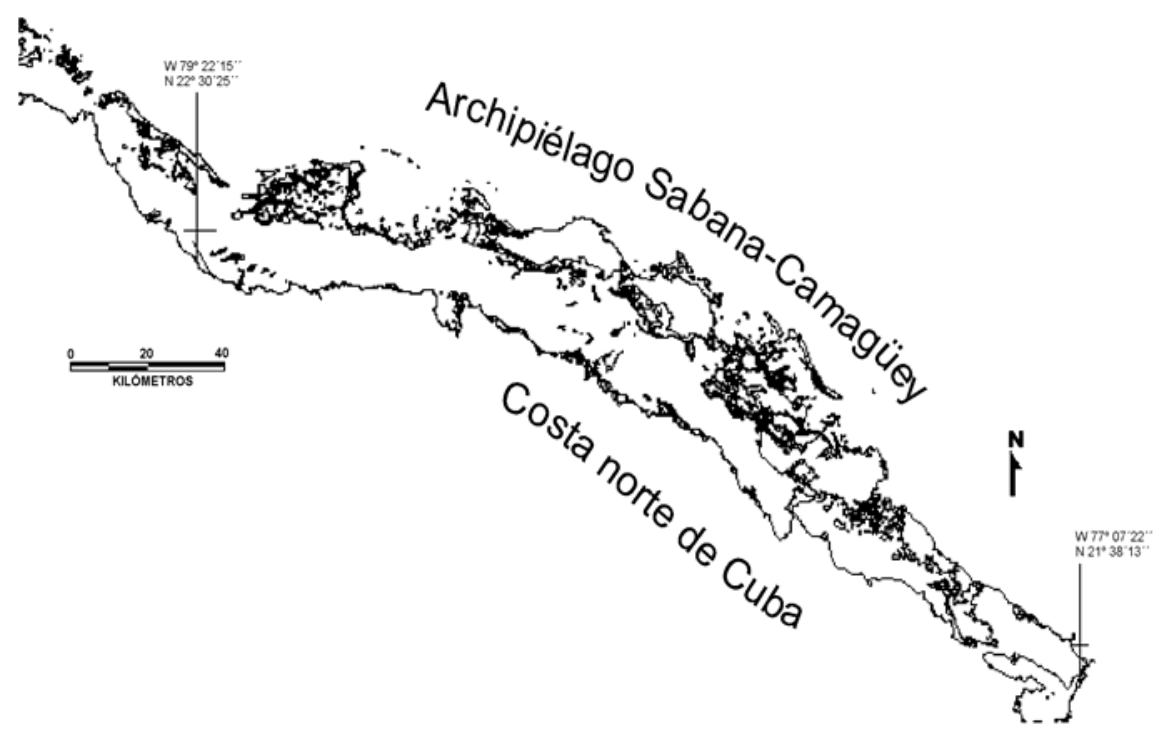

Figura 1. Localización geográfica del Archipiélago Sabana-Camagüey, Cuba.

Se visitaron 21 cayos de la región centro oriental, desde los Cayos de Piedra (Aguada, Lucas, Salinas, Fábrica, Cueva y Ají) (22 $\left.32^{\circ} \mathrm{N}, 79^{\circ} 22^{\prime} \mathrm{W}\right)$ hasta Cayo Sabinal ( $21^{\circ} 38^{\prime} \mathrm{N}, 77^{\circ} 07^{\prime} \mathrm{W}$ ). El área de los cayos varió entre 0.07 Km² (Cayo Fábrica) y $770 \mathrm{Km}^{2}$ (Cayo Romano, la tercera isla más grande del Archipiélago cubano). Las visitas duraron entre dos y quince días donde se efectuaron muestreos en cuevas y solapas; en los casos en que no fue posible la identificación directa, los murciélagos fueron capturados con redes entomológicas. En los cayos más grandes se realizaron, además, capturas nocturnas con redes de niebla ubicadas a nivel del terreno, dentro de la vegetación y en áreas abiertas. Los murciélagos una vez identificados fueron liberados, aunque algunos individuos se depositaron en la Colección de Mamíferos del Instituto de Ecología y Sistemática. Con el fin de detectar restos de murciélagos, todos los nidos o perchas de lechuzas, Tyto alba detectados fueron revisados. A pesar de no haber sido visitados, nosotros consideramos que los cayos del sector más occidental del Archipiélago no deben ser sitios de importancia para los murciélagos porque en su mayoría no tienen tierra firme.

De las 27 especies de murciélagos conocidas en Cuba, nueve se encontraron en cayos del ASC (Cuadro 1). La familia Phyllostomidae presentó el mayor número de especies con seis. Macrotus waterhousii fue la de más amplia distribución, 
detectándose en 14 cayos. Se encontraron individuos solitarios o en pequeños grupos en pequeñas cuevas y solapas de origen marino y estructuras antrópicas. La mayor colonia de esta especie, con aproximadamente 500 individuos, se encontró en la Cueva Pelos de Oro en Cayo Santa María. La segunda especie de más amplia distribución en el Archipiélago de Sabana-Camagüey fue Artibeus jamaicensis, varios individuos fueron capturados en las redes y se encontraron algunos individuos en pequeñas cuevas. Tanto Macrotus waterhousii como Artibeus jamaicensis son oportunistas en la selección del refugio diurno; y utilizan una amplia gama de refugios que van desde cuevas hasta estructuras antrópicas (Silva Taboada, 1979). Este mismo autor registró una colonia de A. jamaicensis instalada en mangle patabán (Laguncularia racemosa) muy cerca de la superficie del mar; por lo que en el grupo insular de Sabana-Camagüey esta especie podría encontrar una alta variedad de refugios.

De los 21 cayos visitados se encontraron murciélagos en 17, y la diversidad fue baja en todos. Los de mayor número de especies fueron Salinas (6 especies) y Santa María (4). No se encontró relación significativa entre el área de los cayos y la riqueza de especies de murciélagos $\left(\mathrm{r}^{2}=0.70, F_{1,16}=0.11, p=0.74\right)$. Al parecer la mayor diversidad de murciélagos en algunos de los Cayos de Piedra en comparación con los de mayor extensión superficial, pudiera estar dada por su cercanía a la costa actual, naturaleza geológica diferente y más antigua que la del resto del archipiélago y similar a la de las colinas tectónicas que se distribuyen a lo largo del litoral como son: Loma de Judas, Punta Caguanes y Lomas de Tasajeras, donde son abundantes los espeleoaccidentes que suministran refugio a los murciélagos.

Al parecer, la complejidad de la vegetación tampoco influye sobre la riqueza de especies de murciélagos que habitan la cayería norte de Cuba. Los cayos de mayor diversidad de formaciones vegetales, como Romano, Sabinal y Guajaba, no presentan un mayor número de especies que aquellos de una gran homogeneidad en la vegetación. Nosotros consideramos que el factor fundamental que determina la composición de la fauna de murciélagos en el Archipiélago de Sabana-Camagüey es la disponibilidad de refugios.

Una de las características de la quiropterofauna cubana es la eficiente utilización de las cuevas como refugios diurnos; de las 27 especies que habitan en Cuba, 16 especies o sea el $60 \%$ las utilizan de manera preferencial y 10 son cavernícolas obligatorias (Silva Taboada, 1979). Producto de la naturaleza geológica de los cayos del ASC las cuevas no son abundantes y las que existen no alcanzan un desarrollo notable. Solo dos especies estrictamente cavernícolas fueron capturadas dentro de cuevas de poco desarrollo, Erophylla sezekorni y Brachyphylla nana. La primera podría utilizar algunos cayos como refugio temporal. Antes y después de marzo de 1995, cuando encontramos una colonia de aproximadamente 80 individuos en la Cueva Pelos de Oro de Cayo Santa María, esta colonia no ha sido vuelta a observar. 


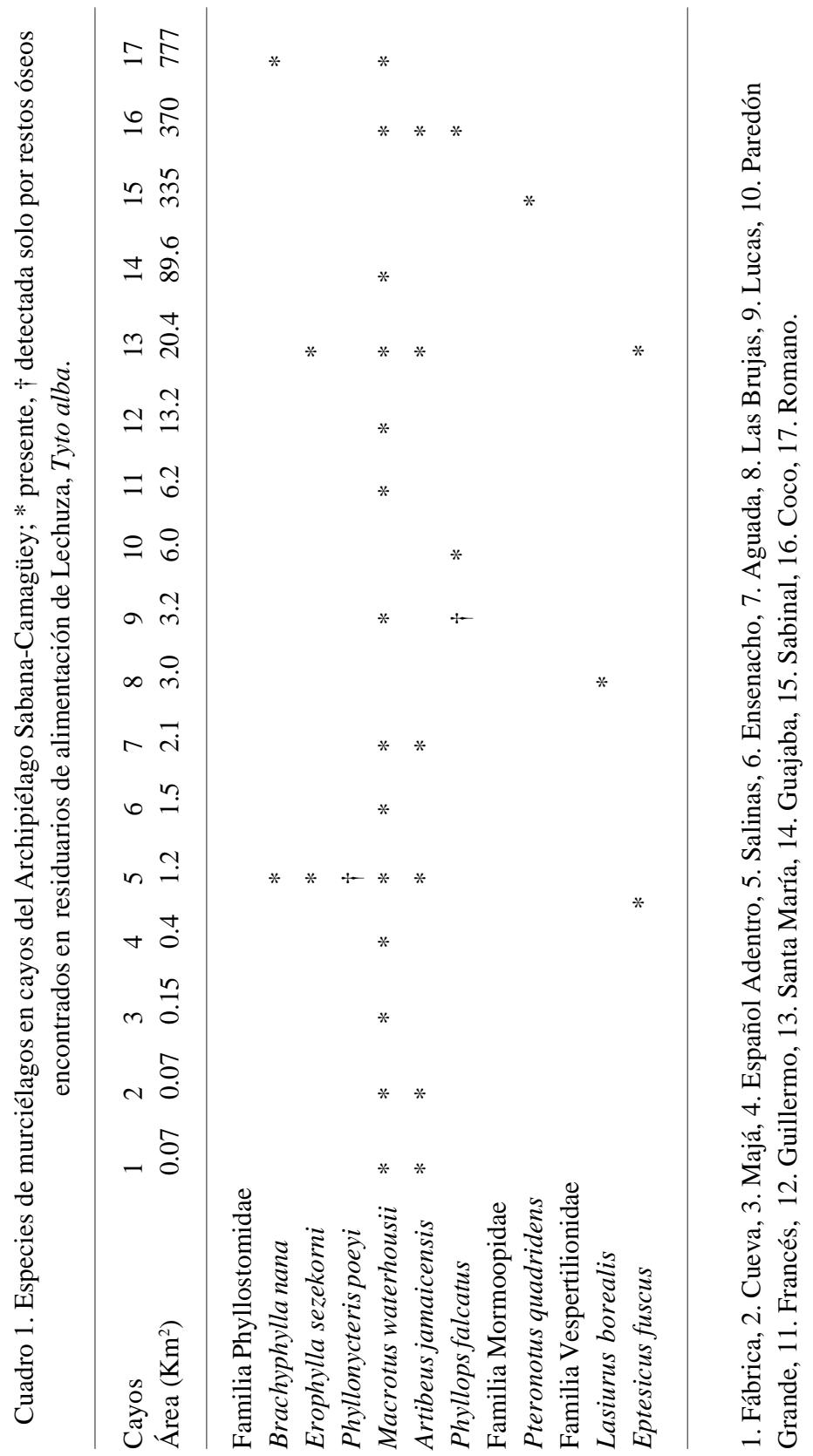


Phyllonycteris poeyi y Pteronotus quadridens, especialistas en el uso de las cuevas de calor como refugio diurno (Sampedro et al., 1976) fueron detectadas en cayos muy próximos a la isla de Cuba. La primera solo fue encontrada en egagrópilas de lechuza en una cueva en Cayo Salinas; y dos individuos de P. quadridens fueron capturados mientras forrajeaban a poca altura en un campamento de guardabosques en Cayo Sabinal. Por la ausencia de cuevas de calor en el ASC, nosotros consideramos que ambas especies utilizan los cayos como habitas de alimentación; aunque es posible que los restos de $P$. poeyi hayan sido trasladados a Cayo Salinas por la lechuza desde zonas costeras cercanas, como es el penicayo de Caguanes donde este murciélago es muy abundante.

La fauna de murciélagos encontrada en los cayos del Archipiélago SabanaCamagüey constituye la tercera parte de la que habita la isla de Cuba; está compuesta por especies que los utilizan como refugios y otras posiblemente como sitios de alimentación. Los murciélagos más abundantes son oportunistas en la selección del refugio diurno y las cavernícolas, presentan un limitado gregarismo cuando se comparan con las poblaciones que habitan la isla de Cuba, además existen especies silvícolas (Phyllops falcatus y Lasiurus borealis), aunque éstas se caracterizan por ser solitarias o poco gregarias. Las especies presente en esta región tienen similitud con la encontrada en otras pequeñas islas de la subregión Antillana; por ejemplo Macrotus waterhousii y Erophylla sezekorni son las especies de mayor distribución en el Banco de las Bahamas (Buden, 1986), y Artibeus jamaicensis y Brachyphylla cavernarum son especies de amplia distribución en las islas de las Antillas Menores (Koopman, 1968); por lo que posiblemente estas presenten adaptaciones a estos pequeños ecosistemas insulares. Este trabajo fue financiado, en su mayor parte, por el Proyecto GEF/PNUD "Protección de la Biodiversidad y Desarrollo Sostenible en el Ecosistema Sabana-Camaguey”.

\section{LITERATURA CITADA}

Alcolado, P. M., E. E. García, y N. Espinosa. 1999. Protección de la biodiversidad y desarrollo sostenible en el Ecosistema Sabana-Camagüey. Proyecto GEF/PNUD, CUB/92/G31, La Habana, Cuba.

Berovides, V., y A. Comas. 1991. The critical condition of hutias in Cuba. Oryx, 25:206-208. Buden, D.W. 1986. Distribution of mammals of Bahamas. Florida Field Naturalist, 14(3):5363.

González, A., N. Manójina y A. Hernández-Marrero. 1994. Mamíferos del Archipiélago de Camagüey, Cuba. Avicennia, 1:51-56.

Koopman, K. F. 1968. Taxonomic and distributional notes on Lesser Antillean Bats. American Museum Novitates, 2333:1-13. 
Sampedro, A., O. Torres, y A. Valdés. 1976. Observaciones ecológicas y etológicas sobre dos especies de murciélagos dominates en las “cuevas calientes” de Cuba. Poeyana, 160:1-18. Silva Taboada, G. 1979. Los murciélagos de Cuba. Editorial Academia, La Habana, Cuba.

Varona, L. S. 1970. Nueva especie y nuevo subgénero de Capromys (Rodentia: Caviomorpha) de Cuba. Poeyana, 73: 1-18. 